\title{
Clinical and cytopathologic characteristics of lymphoid neoplasms involved with serous effusions: a single center experience
}

\section{xubo gong}

the second affiliated hospital, school of medicine, zhejiang university

\section{Sijia Shao}

the second affiliated hospital, school of medicine, zhejiang university

\section{Yanbiao Fu}

the second affiliated hospital, school of medicine, zhejiang university

\section{Lin Wang}

the second affiliated hospital, school of medicine, zhejiang university

\section{Bailai Hu}

the second affiliated hospital, school of medicine, zhejiang university

\section{Xibin Xiao}

the second affiliated hospital, school of medicine, zhejiang university

\section{Lijuan Yan}

the second affiliated hospital, school of medicine, zhejiang university

Xiaoying Zhao ( $\nabla$ zrxz@zju.edu.cn )

\section{Research}

Keywords: Lymphoid neoplasms, diffuse large B-cell lymphoma, myeloma, serous effusions, Chinese

Posted Date: February 12th, 2020

DOI: https://doi.org/10.21203/rs.2.23380/v1

License: (c) (7) This work is licensed under a Creative Commons Attribution 4.0 International License. Read Full License 


\section{Abstract}

Background: Lymphoid neoplasms in serous effusions (SEs) were uncommon. Currently, most reports of lymphoid neoplasms in SEs were from Western countries, but few reports were from China, and the details were still unclear.

Methods: Between January 2004 and December 2019, lymphoid neoplasms diagnosed by cytological methods from specimens of pleural effusions (PEs), ascites, and pericardial effusions in our hospital were reviewed.

Results: 59 patients of lymphoid neoplasms were diagnosed by SEs, the top three causes were diffuse large B-cell lymphoma (DLBCL) $(n=21,35.6 \%)$, myeloma $(n=13,22.0 \%)$, and T-lymphoblastic lymphoma $(n=5$, 8.5\%). In PEs involved with DLBCL, the cytomorphology of DLBCL cells was variable, most PEs were present during tumor course $(92.9 \%)$, bilateral PEs were the predominance $(57.2 \%)$, and the median survival time was only 1.23 months after effusion. In PEs involved with myeloma, nearly all cases had a high ratio of immature to mature plasma cells $(>1.0), \operatorname{lgA}(36.4 \%)$ and light chain $\lambda(36.4 \%)$ were the most frequently found. Bilateral PEs were easily found ( $90.9 \%$ ), and the median survival time was only 1.4 months after effusion. Solitary plasmacytomas with myeloma infiltration in PEs seemed to have a better prognosis than that of plasma cell myeloma.

Conclusion: Some differences are found between our patients and those from Western countries, and more studies involving different ethnic populations could help to elucidate the features of lymphoid neoplasms in SEs.

\section{Introduction}

Cytologic analysis of pleural effusion (PE), ascites, or pericardial effusion was often the first-line diagnostic test performed after an effusion was detected [1-3]. It was simple, safe, fast and cost effective. It reduced all of the possible consequences and complications of a more aggressive biopsy procedure [3, 4]. However, lymphoid neoplasms in serous effusions (SEs) were uncommon, and the diagnosis of lymphoid neoplasms in SEs was still challenging.

Cytopathologic diagnoses could determine whether or not neoplastic cells were present in SEs [2-6], but sometimes it was difficult to determine by cytomorphology alone. For example, indolent lymphoma often mimics a reactive lymphocytosis consisting predominantly of small cells, and plasma cells may present cytomorphologic features nearly identical to mesothelial cells in some effusions. Then a combination of clinical features, morphology, and immunophenotype or other ancillary techniques aided the correct diagnosis of lymphoid neoplasms in SEs [3-5].

Currently, most reports of lymphoid neoplasms in SEs were from Western countries [4-9], but few reports were from China, and the details were still unclear. Racial differences in some hematological malignancies had been reported before $[10,11]$, so it was necessary to reveal the clinical and cytologic features of 
lymphoid neoplasms in SEs from China. In this study, we reviewed the lymphoid neoplasms diagnosed by SEs from our hospital, with a period of sixteen years.

\section{Materials And Methods}

\section{Study Cases}

Between January 2004 and December 2019, lymphoid neoplasms diagnosed by cytological methods from specimens of PEs, ascites, and pericardial effusions in our hospital were reviewed. The presence of lymphoid neoplasms cells in effusions was determined by cytology supplemented by immunocytochemistry (ICC), cell blocks with special studies, flow cytometry (FCM), polymerase chain reaction for clonality, and/ or conventional cytogenetics.

Wright-Giemsa staining and Papanicolaou staining $[3,4]$ were performed on alcohol-fixed smears and/ or liquid-based preparation slides. DiffQuik ${ }^{\circledR}$ staining [12] was performed on air-dry slides for some cases. Haematoxylin-eosin staining was performed on cell block sections. The smears, SurePath ${ }^{\circledR}$ liquid-based preparation slides and cell block sections were reviewed by two experienced pathologists. Data were collected on patients and clinical characteristics as well as results from one or multiple ancillary tests. This investigation was conducted after approval by the institutional review board of the second affiliated hospital, school of medicine, Zhejiang university.

All the diagnoses were in accordance with the criteria of world health organisation classification of tumours of haematopoietic and lymphoid Tissue $(2017)[13,14]$. For patients who had a previous history of lymphoid neoplasms, the results helped to confirm recurrence or transformation to an aggressive subtype. Cases of primary effusion lymphomas, or cases diagnosed by cytomorphology without support of other ancillary test findings had been excluded in advance.

\section{Flow cytometry analysis}

SEs were performed with six-color flow cytometric analysis, using FACSCalibur flow cytometer (BD Biosciences, San Jose, CA, USA) [15]. A panel containing the following fluorescein isothiocyanate, or phycoerythrin-conjugated monoclonal antibodies was used for diagnosis: CD45, CD34, CD33, CD13, CD117, CD38, HLA-DR, CD11c, CD5, CD10, CD7, CD123, CD36, CD15, CD4, CD3, MPO, CD14, CD65, CD56, CD41, CD61, CD64, CD19, CD22, CD138. Cases were considered positive if $20 \%$ or more of the cells expressed the specific antigen in the adequate gate. Daily quality control of instruments had been performed to assure correct results.

\section{Immunocytochemistry (ICC)}

ICC was performed on either SurePath preparation slides or cell block sections with the Envision method [5, 16], diaminobenzidine or 3-amino-9-ethylcarbazole was used as the substrate, and the positive cells were stained brown or red in colour, respectively. The following antibodies were used: MPO, CD3, CD20, CD79a, CD10, CD5, CD138, BCL-6, BCL-2, MUM-1, MYC, CD99, WT1, CK, Ki-67, EMA, Kappa, Lambda, TdT, calretinin, and CyclinD1. 


\section{Polymerase Chain Reaction Assays}

To detect monoclonal gene rearrangements in immunoglobulin $(\mathrm{Ig}) \mathrm{H}$ and $\mathrm{IgK}$, DNA was extracted from samples, and PCR amplification was performed using the BIOMED-2 primers as previously reported $[17,18]$. Appropriate positive, negative, and internal control samples were run with each specimen.

\section{Fluorescence In Situ Hybridization Assays (FISH)}

FISH was performed on the cell block or tissue sections as previously reported [19]. Assays were completed using one or more of the following probes: IGH/BCL2 to detect the $t(14 ; 18)$ (q32;q21.3), IGH/CCND1 to detect $\mathrm{t}(11 ; 14)$ (q13;q32)(dual-color, dual-fusion probes), BCL2, BCL6 and MYC to detect rearrangements (break-apart probe). The FISH results were analyzed by fluorescence microscopy (BX61; Olympus, Center Valley, PA, USA). Concurrent controls were run for each of the probes tested.

\section{Statistics}

Survival was calculated from the onset of effusions to death using the Kaplan-Meier method. Survival curves of DLBCL or myeloma in PEs positive and negative groups were compared with the log-rank test. The skew-distributed data were reported as median and range. Rates were compared with the $\chi 2$ test or Fisher's exact test. $P \leq 0.05$ was considered statistically significant. All data were analyzed using the Statistical Package for the Social Sciences version 16.0 for Windows (SPSS Inc, Chicago, IL).

\section{Results}

\section{Patient characteristics}

Between January 2004 and December 2019, a total of 6849 specimens of PEs $(n=4167)$, ascites $(n=$ 1973), and pericardial effusions $(n=349)$ were analyzed consecutively. $59(0.86 \%)$ patients of lymphoid neoplasms were diagnosed by SEs, with 41 patients diagnosed by PEs, 12 patients by ascitics, and 6 patients by pericardial effusions. The top three causes were DLBCL $(n=21,35.6 \%)$, myeloma $(n=13$, $22.0 \%)$, and T-lymphoblastic lymphoma (T-LBL) $(n=5,8.5 \%)$ (Figure $1 \mathrm{~A})$.

In the 41 patients of lymphoid neoplasms diagnosed by PEs, DLBCL was the commonest cause, identified in $14(34.2 \%)$, followed by myeloma $(n=11,26.9 \%)$, mucosa-associated lymphoid tissue (MALT) lymphoma ( $n$ $=3,7.3 \%)$, T-LBL $(n=2,4.9 \%)$, NK/T-cell lymphoma $(n=2,4.9 \%)$, burkitt lymphoma $(n=2,4.9 \%)$, angioimmunoblastic T-cell lymphoma (AITL) $(n=1,2.4 \%)$, small lymphocytic lymphoma (SLL) $(n=1,2.4 \%)$, mantle cell lymphoma (MCL) $(n=1,2.4 \%)$. In addition, there are three cases of unclassifiable T-lymphoma $(n=3,7.3 \%)$, and one unclassifiable B-lymphoma $(n=1,2.4 \%)$ (Figure 1B).

In the 12 patients diagnosed by ascitics, DLBCL was the commonest cause, identified in 4 (33.4\%), followed by T-LBL $(n=2,16.7 \%)$, myeloma $(n=1,8.3 \%)$, NK/T-cell lymphoma $(n=1,8.3 \%)$, peripheral T-cell lymphoma (PTCL) $(n=1,8.3 \%)$, and SLL $(n=1,8.3 \%)$. In addition, there is one case of unclassifiable Tlymphoma $(n=1,8.3 \%)$ and unclassifiable B-lymphoma $(n=1,8.3 \%)$, respectively (Figure 1 C). 
In the six patients diagnosed by pericardial effusion, DLBCL was the commonest cause, identified in three (50.0\%), followed by T-LBL $(n=1,16.7 \%)$, myeloma $(n=1,16.7 \%)$. One case of T-lymphoma was unclassified ( $n=1,16.6 \%$ ) (Figure 1D).

\section{Characteristics of DLBCL in PEs}

In our series, DLBCL was the most frequently found $(n=21,35.6 \%)$. As most of the cases were from PEs, so we next focused on the characteristics of DLBCL in PEs ( $n=14)$. It showed that 9 of $14(64.3 \%)$ patients had a high percentage of immature lymphocytes (>50\%) in PEs, and papillary projection of nuclei $(13 / 14,92.9 \%)$, cytoplasmic or nuclear vacuoles $(10 / 14,71.4 \%)$ were frequently found (Figure 2, Table 1).

Another 25 DLBCL patients without involvement with lymphoma cells in PEs were selected consecutively in our hospital for comparison. It showed that significant differences of cases with mesothelial cells $<20 \%$ (78.6\% vs 24.0\%, $P=0.002)$, presence of apoptosis (78.6\% vs $8.0 \%, P=0.000)$, IPI scores $\geq 3(92.8 \%$ vs $44.0 \%, P=0.003)$, Stage $\geq 3(100 \%$ vs $48.0 \%, P=0.001)$, bilateral PEs $(57.2 \%$ vs $24.0 \%, P=0.038)$, and survival $\leq 6$ months after effusion ( $81.8 \%$ vs $11.1 \%, P=0.000)$ were found between DLBCL in PEs positive and negative groups (Table 2).

By Kaplan-Meier analysis, it showed that the survival time after effusion in PEs positive group was significantly shorter than that in PEs negative group (median, 1.23 vs 14.43 months, $P=0.000$ ) (Figure 4).

\section{Characteristics of myeloma in PEs}

Myeloma was the second cause $(n=13,29.3 \%)$ of SEs in our series. As most of myeloma were found in PEs $(n=11)$, so we also studied the features of myeloma in PEs. It showed that 6 of $11(54.5 \%)$ patients had a high percentage of plasma cells ( $>50 \%)$ in PEs, but papillary projection of nuclei, cytoplasmic or nuclear vacuoles were hardly found (Figure 3, Table 3).

Another 18 myeloma patients without involvement with myeloma cells in PEs were selected consecutively in our hospital for comparison. It showed that significant differences of cases with mesothelial cells $<20 \%$ (72.7\% vs $16.7 \%, P=0.003)$, presence of apoptosis $(72.7 \%$ vs $11.1 \%, P=0.001)$, presence of mitoses $(81.8 \%$ vs 5.6\%, $P=0.000)$, Calcium $>2.6 \mathrm{mmol} / \mathrm{L}(81.8 \%$ vs $27.8 \%, P=0.005)$, bilateral PEs $(90.9 \%$ vs $16.7 \%, P=$ $0.000)$, the median percentage of plasma cells in bone marrow (BM) $(76.5 \% v s 32.0 \%, P=0.003)$, and the survival after effusion $\leq 6$ months $(81.8 \%$ vs $11.1 \%, P=0.000)$ were found between myeloma in PEs positive and negative groups (Table 4 and 5).

By Kaplan-Meier analysis, it showed that the survival time after effusion in PEs positive group was significantly shorter than that in PEs negative group (median, 1.4 vs 19.2 months, $P=0.029$ ) (Figure 4).

\section{Discussion}

SEs occur in a number of malignancies, but lymphoid neoplasms in effusions are still uncommon. Recently, the data of lymphoid neoplasms in effusions are lacking from many parts of the world. It has been reported mostly as single case description or in reviews of multiple case reports from different institutions [20-24]. To 
the best of our knowledge, this study is the largest series of lymphoid neoplasms in effusions reported from China.

In our series, B-cell neoplasms in effusions are more frequently found than T-cell or NK-cell neoplasms, which is contrast to some reports from Western countries $[1,22,23]$. The top three lymphoid neoplasms are DLBCL, myeloma, and T-LBL in order. DLBCL is the most frequently found not only in PEs, but also in ascites and pericardial effusions. Our hospital is not a specialized hospital but one famous general hospital in the east of China, so the specimens are unbiased. Nearly two-thirds of our patients with lymphoid neoplasms are diagnosed by PEs, therefore we pay more attention to the features of DLBCL and myeloma in PEs.

The cytomorphology of DLBCL cells in PEs is variable. Papillary projection of nuclei, cytoplasmic or nuclear vacuoles, mitoses and apoptosis are present in more than two-thirds of our patients, but these features can also be easily seen in other lymphomas, such as Burkitt lymphoma, MALT lymphoma [25]. Some DLBCL cells also present cytomorphologic features similar to undifferentiated carcinoma or sarcoma, the distinction is that most DLBCL cells distributed separately or scatteredly, rather than nest-like distribution as carcinoma or sarcoma. No unique morphologic feature of DLBCL cells in PEs is found in our series, and the correct diagnoses require the combination of cytomorphologic and other ancillary test findings.

In our series, IPI scores $\geq 3$ and stage $\geq 3$ are present nearly in all DLBCL patients involved with PEs, and bilateral PEs are found in more than half of the patients, which indicate the seriousness of this disease. Contrast to some other reports [4,26], 92.9\% cases with effusions are present during tumor course in our study. BM involvement of DLBCL cells are usually more frequently found than PEs [25], but in our DLBCL patients with lymphoma cells in PEs, less than one-thirds of patients are found with BM involvement. The reason is unclear, maybe DLBCL in our patients invade the thoracic cavity more easily. Consistent with Chen et al [26], the prognosis of our patients with DLBCL in PEs is very poor, with the median survival time of 1.23 months after effusion. RCHOP-like treatment seems to have no significant improvement of survival.

PEs due to plasma cells infiltration are rare, with approximately 80 cases reported worldwide $[8,27,28]$. It may result from extension of adjacent subcutaneous, skeletal, or parenchymal plasmocytomas into the pleural space [8,13]. The cytomorphology of malignant plasma cells includes nuclear polymorphism, prominent nucleoli or asynchronous maturation of the nucleus in relation to the cytoplasm, mitoses and apoptosis, but papillary projection of nuclei, cytoplasmic or nuclear vacuoles are hardly found in our study. In addition to the help of other ancillary findings, the high ratio of immature to mature plasma cells $(>1.0)$ are very helpful in differentiating reactive from malignant plasma cells infiltrates.

Our study shows that paraprotein type of $\lg \mathrm{A}(36.4 \%)$ and light chain $\lambda(36.4 \%)$ are the most frequently found, in contrast to the IgG predominance reported elsewhere $[8,21,28]$. The median percentage of plasma cells in bone marrow is significantly higher in PEs positive group than that in PEs negative group $(76.5 \% \mathrm{vs}$ $32.0 \%$ ). It has been reported that left-sided PEs caused by myeloma are mostly seen in Western countries [29,30], but bilateral PEs (90.9\%) are more easily found in our study. The prognosis of our patients with myeloma in PEs is very poor, the median survival time is only 1.4 months after effusion. 
Interestingly, there is an unusual case in our series. A 69 years-old female patient with a right-sided pleural mass is diagnosed as solitary plasmacytomas with involvement of PEs, no monoclonal immunoglobulin or skeletal lesions was found. She received five courses of local chemotherapy with melphalan and prednisone by intrapleural injection, followed by two course of cisplatin and dexamethasone. Now the patient is still alive, with a survival time more than six years. It seems that solitary plasmacytomas with myeloma infiltration in PEs has a better prognosis than that of plasma cell myeloma. Due to the rarity of solitary plasmacytomas involved with PEs, it should be confirmed with more cases.

In conclusion, we reveal the prevalence of lymphoid neoplasms in SEs from China, and show the clinical and cytologic characteristics of DLBCL or myeloma involved with PEs. Some differences do exist between our patients and those from Western countries, and more studies from different ethnic populations should help to elucidate the features of lymphoid neoplasms in SEs.

\section{Declarations}

\section{Ethics approval and consent to participate}

Our study was approved by the ethics committees of the second affiliated hospital, school of medicine, zhejiang university, according to the guidelines of the Declaration of Helsinki. Additional patient consent for this retrospective study was not required.

\section{Patient content for publication}

Not applicable.

\section{Availability of data and materials}

All data generated or analyzed during this study are included in this published article

\section{Competing interests}

The authors declare that they have no competing interests

\section{Funding}

This work was supported by national natural science foundation of China (No. 81400107).

\section{Authors' contributions}

Xiaoying Zhao conceived and designed the study. Xubo Gong, Bailai Hu, Sijia Shao, Yanbiao Fu, Lin Wang performed the study, Lijuan Yan prepared figures, interpreted the data, Xubo Gong wrote the manuscript. All authors read and approved the final manuscript.

\section{Acknowledgement}

We thank Drs Zhu L, Xu H, and Jin L for their excellent technical assistance. 


\section{Abbreviations}

SEs, serous effusions; PEs, pleural effusions; DLBCL, diffuse large B-cell lymphoma; ICC, immunocytochemistry; FCM, flow cytometry; Ig, immunoglobulin; FISH, Fluorescence In Situ Hybridization Assays; T-LBL, T-lymphoblastic lymphoma; MALT, mucosa-associated lymphoid tissue; AITL, angioimmunoblastic T-cell lymphoma; SLL, small lymphocytic lymphoma; MCL, mantle cell lymphoma; PTCL, peripheral T-cell lymphoma

\section{References}

[1] Das DK. Serous effusions in malignant lymphomas: a review. Diagn cytopathol. 2006; 34 (5): 335-347.

[2] Patel T, Patel P, Mehta S, et al. The value of cytology in diagnosis of serous effusions in malignant lymphomas: an experience of a tertiary care center. Diagn cytopathol. 2019; 47 (8): 776-782.

[3] Savvidou K, Dimitrakopoulou A, Kafasi N, et al. Diagnostic role of cytology in serous effusions of patients with hematologic malignancies. Diagn cytopathol. 2019; 47 (5): 404-411.

[4] Johnston WW. The malignant pleural effusion. A review of cytopathologic diagnoses of 584 specimens from 472 consecutive patients. Cancer. 1985; 56 (4): 905-909.

[5] Jing X, Li QK, Bedrossian U, Michael CW. Morphologic and immunocytochemical performances of effusion cell blocks prepared using 3 different methods. Am J Clin Pathol. 2013; 139 (2): 177-182.

[6] Jones D, Weinberg DS, Pinkus GS, Renshaw AA. Cytologic diagnosis of primary serous lymphoma. Am J Clin Pathol. 1996; 106 (3): 359-364.

[7] Alexandrakis MG, Passam FH, Kyriakou DS, Bouros D. Pleural effusions in hematologic malignancies. Chest. 2004; 125 (4): 1546-1555.

[8] Kyle RA, Rajkumar SV. Multiple myeloma. Blood. 2008; 111:2962-2972.

[9] Tong LC, Ko HM, Saieg MA, et al. Subclassification of lymphoproliferative disorders in serous effusions: A 10-year experience. Cancer cytopathol. 2013; 121 (5): 261-270.

[10] Gong X, Lu X, Xiao X, et al. Clinicopathologic characteristics of prefibrotic early primary myelofibrosis in Chinese patients. Hum Pathol. 2014; 45: 498-503.

[11] Cheng $Y$, Wang $Y$, Wang $H$, Chen $Z$ et al. Cytogenetic profile of de novo acute myeloid leukemia: a study based on 1432 patients in a single institution of China. Leukemia. 2009; 23: 1801- 1806.

[12] Li J, Zhang W, Zhao S, et al. The Accuracy of diagnosing burkitt lymphoma in serous effusion specimen: A cytological-histological correlation with ancillary studies. Cytopathology. 2019; 30 (4): 378-384.

[13] McKenna RW, Kyle RA, Kuehl WM, et al. Plasma cell neoplasms. In: Swerdlow SH, Campo E, Harris NL, eds. WHO Classification of Tumours of Haematopoietic and Lymphoid Tissues. Lyon: IARC. 2017: 241-258. 
[14] Arber DA, Orazi A, Hasserjian R, et al. The 2016 revision to the World Health Organization classification of myeloid neoplasms and acute leukemia. Blood. 2016; 127(20): 2391-405.

[15] Gong X, Yu T, Tang Q, et al. Unusual findings of acute myeloid leukemia with inv(3)(q21q26.2) or t(3;3) (q21;q26.2): A multicenter study. Int J Lab Hematol. 2019; 41(3): 380-386.

[16] Santos GC, Longatto-Filho A, Carvalho LV, et al. Immunocytochemical study of malignant lymphoma in serous effusions. Acta Cytol. 2000; 44(4): 539-542.

[17] Chou WC, Tang JL, Lin LI, Yao M et al. Nucleophosmin mutations in de novo acute myeloid leukemia: the age-dependent incidences and the stability during disease evolution. Cancer Res. 2006; 66(6): 33103316.

[18] Chen CY, Lin LI, Tang JL, et al. RUNX1 gene mutation in primary myelodysplastic syndrome: the mutation can be detected early at diagnosis or acquired during disease progression and is associated with poor outcome. Br J Haematol. 2007; 139(3):405-414.

[19] Gong X, Lu X, Wu X, et al. Role of bone marrow imprints in hematological diagnosis: a detailed study of 3781 cases. Cytopathology. 2012; 23(2):86-95.

[20] Jiang Y, Xie W, Hu K, et al. An aggressive form of non-Hodgkin's lymphoma with pleural and abdominal chylous effusions: A case report and review of the literature. Oncol let. 2013; 6 (4): 1120-1122.

[21] Shirai T, Hashizume I, Kasamatsu N, et al. A case of bence-Jones protein-lambda positive multiple myeloma complicated by abnormal plasma cells in pleural effusion. Nihon Kokyuki Gakkai Zasshi. 1998; 36: 176-181.

[22] Uchiyama K, Kobayashi Y, Tanaka R, et al. Primary malignant lymphoma of the central nervous system presenting with ascites and pleural effusion. Hematologica (Budap). 2000; 30: 143-148.

[23] Watanabe N, Sugimoto N, Matsushita A, et al. Association of intestinal lymphoma and ulcerative colitis. Intern Med. 2003; 42: 1183-1187.

[24] Su X-Y, Huang J, Jiang Y, et al. Serous effusion cytology of extranodal natural killer/T-cell lymphoma. Cytopathology. 2011; 23 (2): 96-102.

[25] Gascoyne RD, Campo E, Jaffe ES, et al. Diffuse large B-cell lymphoma, NOS. In: Swerdlow SH, Campo E, Harris NL, eds. WHO Classification of Tumours of Haematopoietic and Lymphoid Tissues. Lyon: IARC. 2017: 291-297.

[26] Chen YP, Huang HY, Lin KP, et al. Malignant effusions correlate with poorer prognosis in patients with diffuse large B-cell lymphoma. Am J Clin Pathol. 2015; 143 (5): 707-715.

[27] Harbhajanka A, Brickman A, Park J, et al. Cytomorphology, clinicopathologic, and cytogenetics correlation of myelomatous effusion of serous cavities: A retrospective review. Diagn Cytopathol. 2016; 44 
(9): 742-747.

[28] Kyle RA, Rajkumar SV. Multiple myeloma. N Engl J Med. 2004; 351: 1860-1873.

[29] Kintzer JS Jr, Rosenow EC 3rd, Kyle RA: Thoracic and pulmonary abnormalities in multiple myeloma. A review of 958 cases. Arch Intern Med. 1978; 138: 727-730.

[30] lannitto E, Minardi V, Tripodo C. Use of intrapleural bortezomib in myelomatous pleural effusion. $\mathrm{Br} \mathrm{J}$ Haematol. 2007; 139: 621-622.

\section{Tables}

Table 1. Cytological features of DLBCL cells in pleural effusions (PEs)

\begin{tabular}{|l|l|l|}
\hline \multirow{2}{*}{ Cytological features } & DLBCL in PEs (+) & DLBCL in PEs (-) \\
\cline { 2 - 3 } & $\mathrm{n}=14$ & $\mathrm{n}=25$ \\
\hline Presence of mitoses & $12 / 14(85.7 \%)^{* *}$ & $2 / 25(8.0 \%)$ \\
\hline Presence of apoptosis & $11 / 14(78.6 \%)^{* *}$ & $2 / 25(8.0 \%)$ \\
\hline Mesothelial cells & & \\
\hline$<20 \%$ & $11 / 14(78.6 \%)^{* *}$ & $6 / 25(24.0 \%)$ \\
\hline $20 \% \sim 50 \%$ & $2 / 14(14.3 \%)$ & $9 / 25(36.0 \%)$ \\
\hline$>50 \%$ & $1 / 14(7.1 \%)^{*}$ & $10 / 25(40.0 \%)$ \\
\hline Immature lymphocytes & & \\
\hline$<20 \%$ & $2 / 14(14.3 \%)$ & NA \\
\hline $20 \% \sim 50 \%$ & $3 / 14(21.4 \%)$ & NA \\
\hline$>50 \%$ & $9 / 14(64.3 \%)$ & NA \\
\hline papillary projection of nuclei & $13 / 14(92.9 \%)$ & NA \\
\hline cytoplasmic or nuclear vacuoles & $10 / 14(71.4 \%)$ & NA \\
\hline
\end{tabular}

NA, not applicable; (+), positive, (-), negative;

Compared with DLBCL in PEs (-) group, $* P<0.05$, ** $P<0.01$

Table 2. The clinical and laboratory features of patients with DLBCL cells in pleural effusions (PEs) 


\begin{tabular}{|l|l|l|}
\hline Clinical and other findings & DLBCL in PEs (+) & DLBCL in PEs (-) \\
\cline { 2 - 3 } & $\mathrm{n}=14$ & $\mathrm{n}=25$ \\
\hline Sex, male & $9 / 14(64.3 \%)$ & $14 / 25(56.0 \%)$ \\
\hline Age (median, range), years & $62(23-79)$ & $53(20-86)$ \\
\hline Tumor sites (extranodal) & $5 / 14(35.7 \%)$ & $7 / 25(28.0 \%)$ \\
\hline LDH >248U/L & $14 / 14(100 \%)$ & $23 / 25(92.0 \%)$ \\
\hline MYC rearrangement & $4 / 10(40.0 \%)$ & $3 / 19(15.8 \%)$ \\
\hline Bcl-6 rearrangement & $2 / 10(20.0 \%)$ & $3 / 19(15.8 \%)$ \\
\hline Bcl-2 rearrangement & $1 / 10(10.0 \%)$ & $0 / 19$ \\
\hline IPI scores $\geq 3$ & $13 / 14(92.8 \%)^{* *}$ & $11 / 25(44.0 \%)$ \\
\hline Stage $\geq 3$ & $14 / 14(100 \%)^{* *}$ & $12 / 25(48.0 \%)$ \\
\hline BM involvement & $3 / 13(23.1 \%)$ & $3 / 23(13.0 \%)$ \\
\hline Cell of origin GC & $3 / 14(21.4 \%)$ & $9 / 25(36.0 \%)$ \\
\hline Effusion & & \\
\hline at diagnosis & $1 / 14(7.1 \%)$ & $1 / 25(4.0 \%)$ \\
\hline during tumor course & $13 / 14(92.9 \%)$ & $24 / 25(96.0 \%)$ \\
\hline Location of PEs & & \\
\hline left & $5 / 14(35.7 \%)$ & $8 / 25(32.0 \%)$ \\
\hline right & $1 / 14(7.1 \%)^{*}$ & $11 / 25(44.0 \%)$ \\
\hline bilateral & $8 / 14(57.2 \%)^{*}$ & $6 / 25(24.0 \%)$ \\
\hline RCHOP-like treatment & $6 / 14(42.9 \%)$ & $12 / 25(48.0 \%)$ \\
\hline Survival after effusion & & $3 / 25(12.0 \%)$ \\
\hline$\leq 6$ months & $11 / 14(78.6 \%)^{* *}$ & $6 / 25(24.0 \%)$ \\
\hline $6 \sim 12$ months & $1 / 14(7.1 \%)$ & $16 / 25(64.0 \%)$ \\
\hline$\geq 12$ months & $2 / 14(14.3 \%)^{* *}$ & \\
\hline
\end{tabular}

$(+)$, positive; (-), negative;

Compared with DLBCL in PEs (-) group, $* P<0.05$, ** $P<0.01$

Table 3. Cytological features of myeloma cells in pleural effusions (PEs) 


\begin{tabular}{|l|l|l|}
\hline Cytological features & Myeloma in PEs (+) & Myeloma in PEs (-) \\
\cline { 2 - 3 } & $\mathrm{n}=11$ & $\mathrm{n}=18$ \\
\hline Presence of mitoses & $9 / 11(81.8 \%)^{* *}$ & $1 / 18(5.6 \%)$ \\
\hline Presence of apoptosis & $8 / 11(72.7 \%)^{* *}$ & $2 / 18(11.1 \%)$ \\
\hline Mesothelial cells & & \\
\hline$<20 \%$ & $8 / 11(72.7 \%)^{* *}$ & $3 / 18(16.7 \%)$ \\
\hline $20 \% \sim 50 \%$ & $2 / 11(18.2 \%)$ & $6 / 18(33.3 \%)$ \\
\hline$>50 \%$ & $1 / 11(9.1 \%)^{*}$ & $9 / 18(50.0 \%)$ \\
\hline Plasma cells (total) & & \\
\hline$<20 \%$ & $2 / 11(18.2 \%)$ & NA \\
\hline $20 \% \sim 50 \%$ & $3 / 11(27.3 \%)$ & NA \\
\hline$>50 \%$ & $6 / 11(54.5 \%)$ & NA \\
\hline papillary projection of nuclei & $1 / 11(9.1 \%)$ & NA \\
\hline cytoplasmic or nuclear vacuoles & 0 & NA \\
\hline ratio of immature to mature plasma cells $>1.0$ & $10 / 11(90.9 \%)$ & NA \\
\hline
\end{tabular}

NA, not applicable; (+), positive; (-), negative;

Compared with myeloma in PEs (-) group, ${ }^{*} P<0.05$, $* * P<0.01$

Table 4. The laboratory findings of myeloma patients with pleural effusions (PEs) 


\begin{tabular}{|l|l|l|}
\hline Laboratory findings & Myeloma in PEs (+) & Myeloma in PEs (-) \\
\cline { 2 - 3 } & $\mathrm{n}=11$ & $\mathrm{n}=18$ \\
\hline Paraprotein type & & \\
\hline IgG & $2 / 11(18.2 \%)$ & $8 / 18(44.4 \%)$ \\
\hline IgA & $4 / 11(36.4 \%)$ & $5 / 18(27.8 \%)$ \\
\hline IgD & 0 & $1 / 18(5.6 \%)$ \\
\hline lgMh & 0 & 0 \\
\hline light chain $\lambda$ & 0 & 0 \\
\hline none & $4 / 11(36.4 \%)$ & $4 / 18(22.2 \%)$ \\
\hline Creatinine>88.0 $\mu$ mol/L & $1 / 11(9.0 \%)$ & 0 \\
\hline Calcium $>2.6 m m o l / L$ & $6 / 11(54.5 \%)$ & $4 / 18(22.2 \%)$ \\
\hline$\beta 2-m i c r o g l o b u l i n ~>3.0 m g / L$ & $9 / 11(81.8 \%)^{* *}$ & $5 / 18(27.8 \%)$ \\
\hline Bone marrow plasma cells (median, range)\% & $76.5(1.5,94.0)^{* *}$ & $32.0(0.5,92.0)$ \\
\hline Abnormal genetics testing G-banded karyotype & $5 / 11(45.5 \%)$ & $3 / 18(16.7 \%)$ \\
\hline
\end{tabular}

$(+)$, positive; (-), negative;

Compared with myeloma in PEs (-) group, $* P<0.05$, ${ }^{* *} P<0.01$

Table 5. The clinical features of patients with myeloma cells in pleural effusions (PEs) 


\begin{tabular}{|l|l|l|}
\hline \multirow{2}{*}{ Clinical findings } & Myeloma in PEs (+) & Myeloma in PEs \\
\cline { 2 - 3 } & $\mathrm{n}=11$ & $\mathrm{n}=18$ \\
\hline Diagnosis & & \\
\hline Plasma cell myeloma & $10 / 11(90.9 \%)$ & $18 / 18(100 \%)$ \\
\hline Solitary myeloma & $1 / 11(9.1 \%)$ & 0 \\
\hline Sex, male & $8 / 11(72.7 \%)$ & $10 / 18(55.5 \%)$ \\
\hline Age (median, range), year & $67(46,84)$ & $58(42,89)$ \\
\hline ISS stage & & \\
\hline I & $1 / 11(9.1 \%)$ & $2 / 18(11.1 \%)$ \\
\hline II & $2 / 11(18.2 \%)$ & $5 / 18(27.8 \%)$ \\
\hline III & $8 / 11(72.7 \%)$ & $11 / 18(61.1 \%)$ \\
\hline Effusion & & \\
\hline at diagnosis & $2 / 11(18.2 \%)$ & 0 \\
\hline during tumor course & $9 / 11(81.8 \%)$ & $18 / 18(100 \%)$ \\
\hline Location of PEs & & \\
\hline left & 0 & $6 / 18(33.3 \%)$ \\
\hline right & $1 / 11(9.1 \%)^{*}$ & $9 / 18(50.0 \%)$ \\
\hline bilateral & $10 / 11(90.9 \%)^{* *}$ & $3 / 18(16.7 \%)$ \\
\hline Treatment with bortezomib containing regimens & $6 / 11(42.9 \%)$ & $12 / 18(48.0 \%)$ \\
\hline Survival after effusion & & \\
\hline$\leq 6$ months & $9 / 11(81.8 \%)^{* *}$ & $2 / 18(11.1 \%)$ \\
\hline $6 \sim 12$ months & $1 / 11(9.1 \%)$ & $4 / 18(22.2 \%)$ \\
\hline$\geq 12$ months & $1 / 11(9.1 \%)^{* *}$ & $12 / 18(66.7 \%)$ \\
\hline
\end{tabular}

$(+)$, positive; (-), negative;

Compared with myeloma in PEs (-) group, $* P<0.05$, ** $P<0.01$

\section{Figures}


A

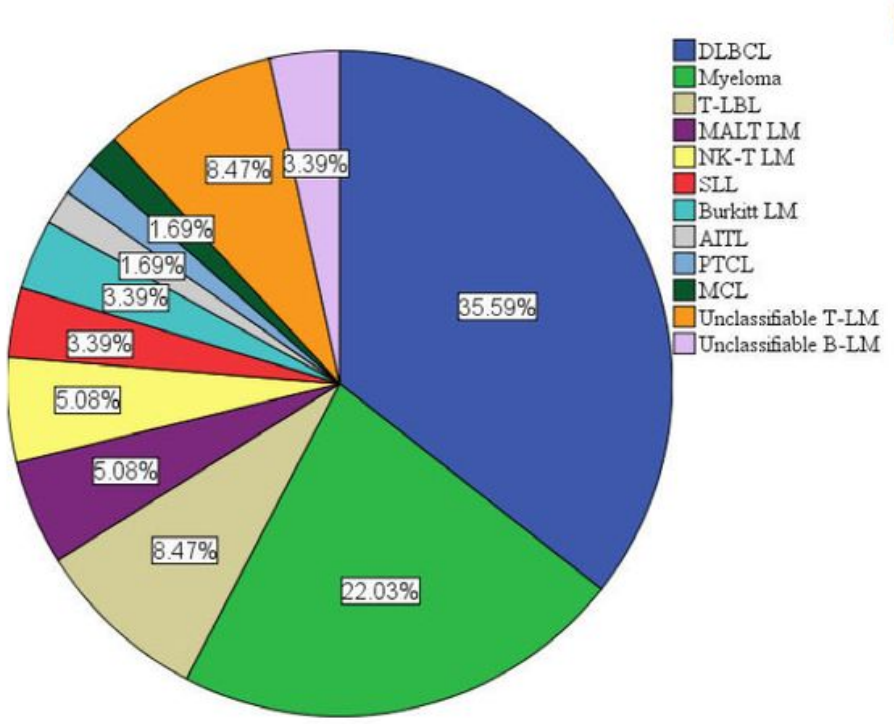

$\mathrm{C}$

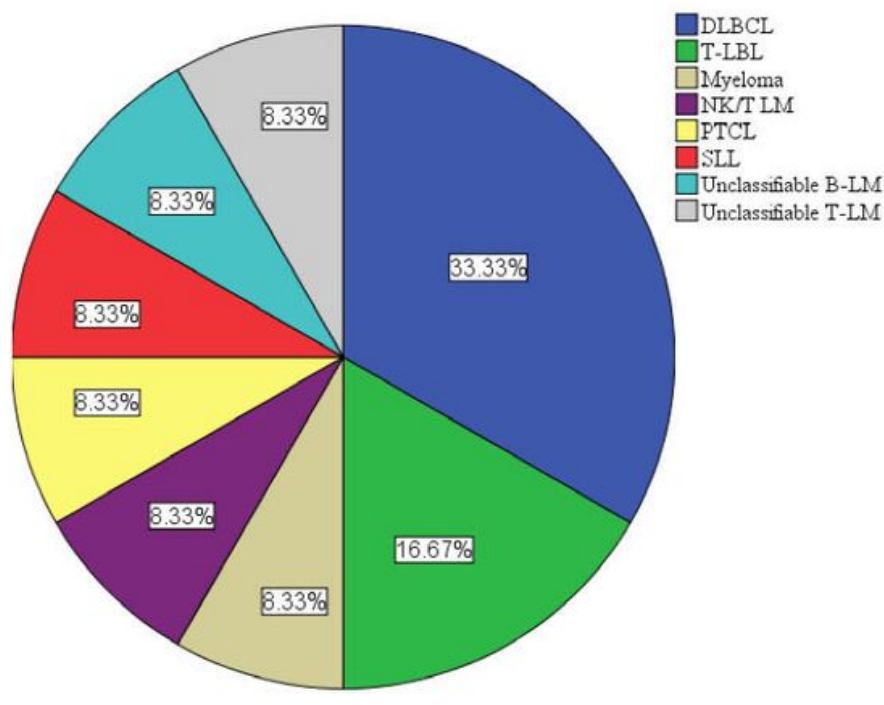

B
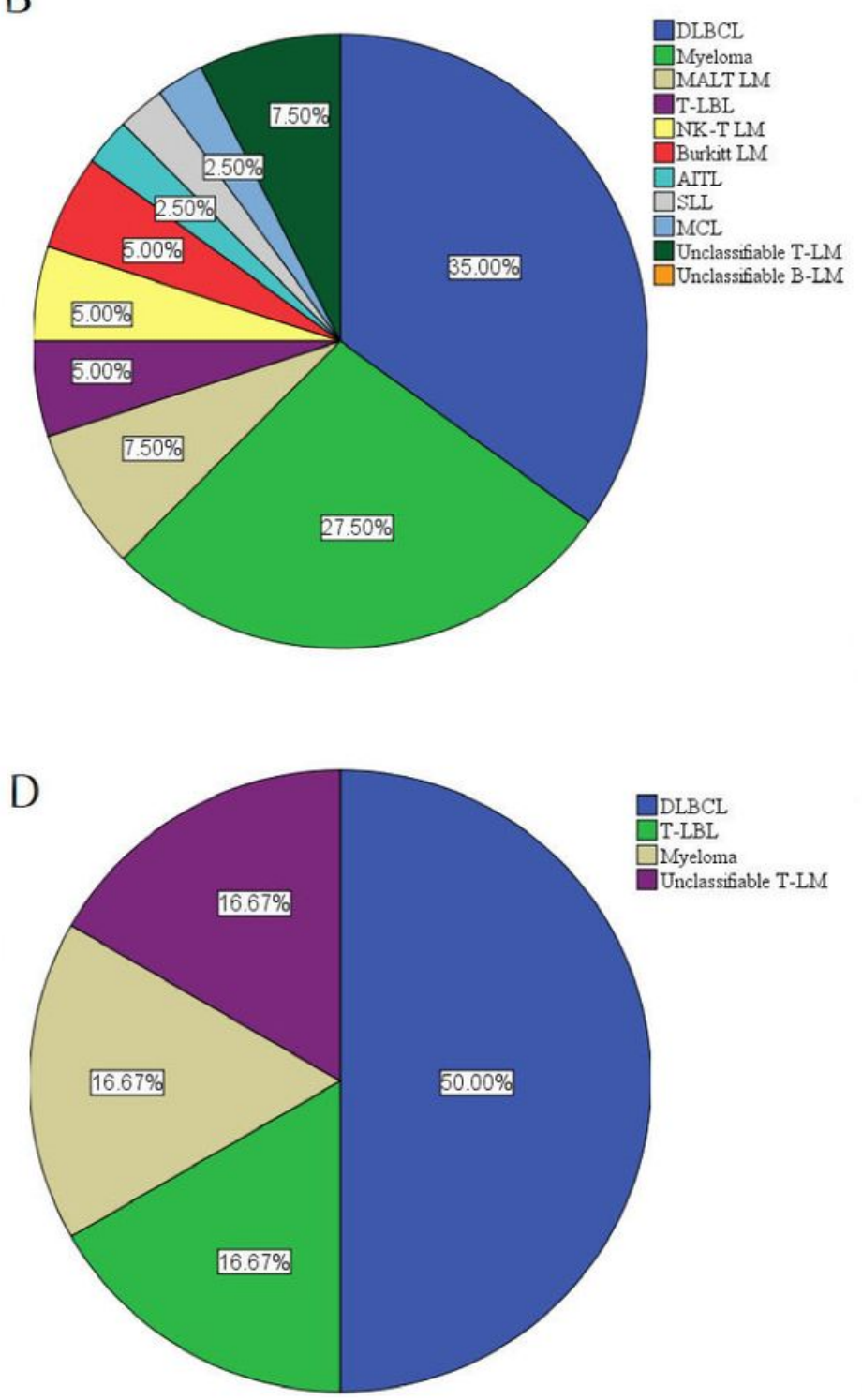

\section{Figure 1}

The prevalence of lymphoid neoplasms in serous effusions (SEs). A total of 59 patients of lymphoid neoplasms were diagnosed by SEs, the top three causes were diffuse large B-cell lymphoma (DLBCL) ( $n=$ 21), myeloma $(n=13)$, and T-lymphoblastic lymphoma $(T-L B L)(n=5)(A) .41$ patients of lymphoid neoplasms were diagnosed by pleural effusions, the top three causes were DLBCL $(n=14)$, myeloma $(n=$ $11)$, and mucosa-associated lymphoid tissue (MALT) lymphoma $(n=3)(B) .12$ patients were diagnosed by ascitics, the top three causes were DLBCL $(n=4), T-L B L(n=2)$ and myeloma $(n=1)(C)$. Six patients were diagnosed by pericardial effusion, the top three causes were DLBCL $(n=3), T-L B L(n=1)$, and myeloma $(n=$ 1) (D). 
A

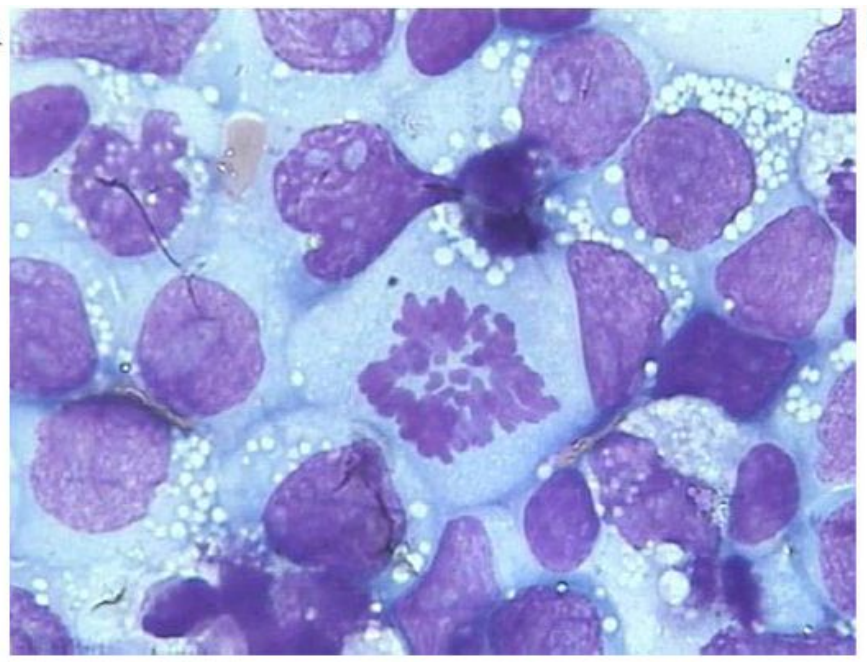

$\mathrm{C}$

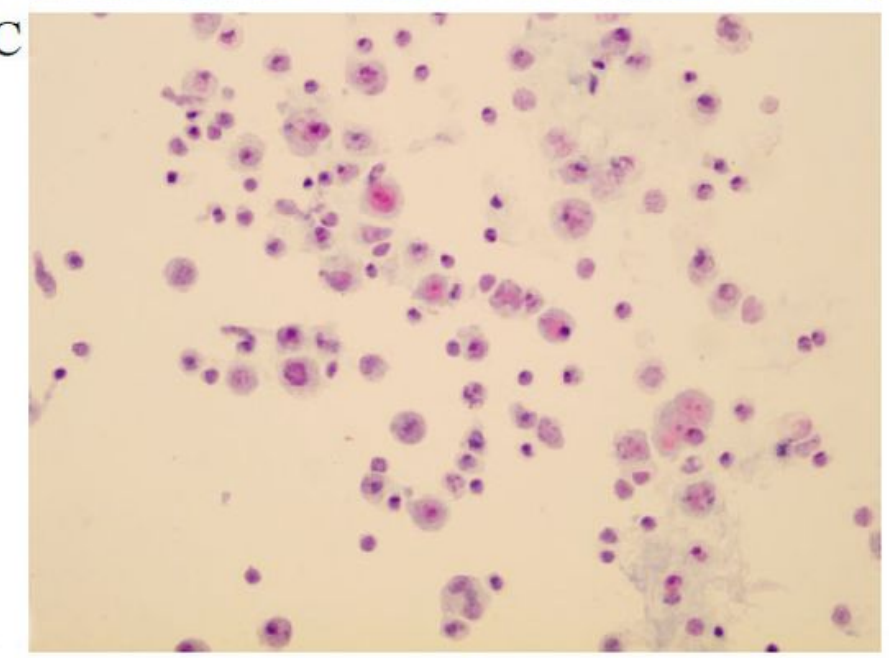

$\mathrm{E}$

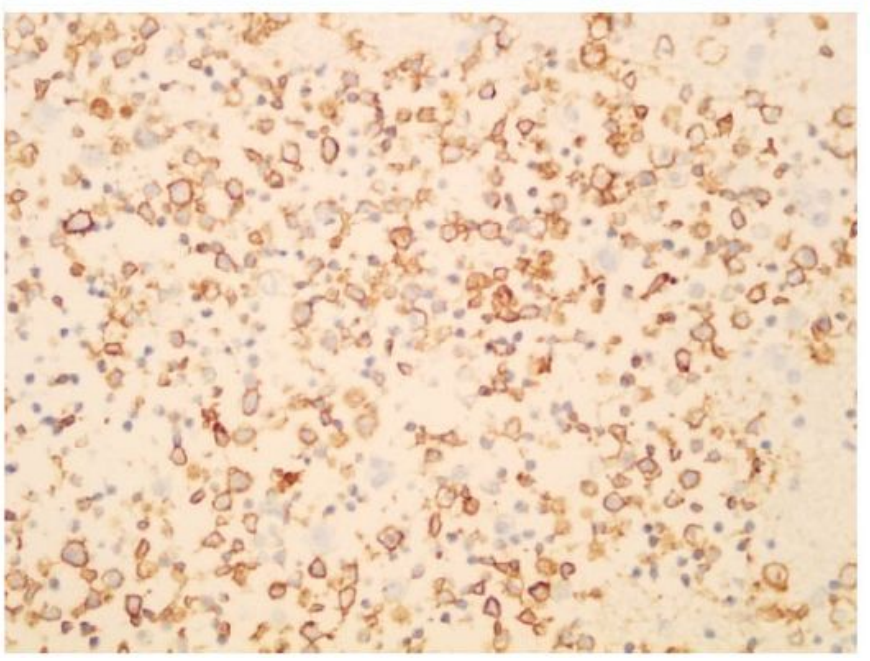

B

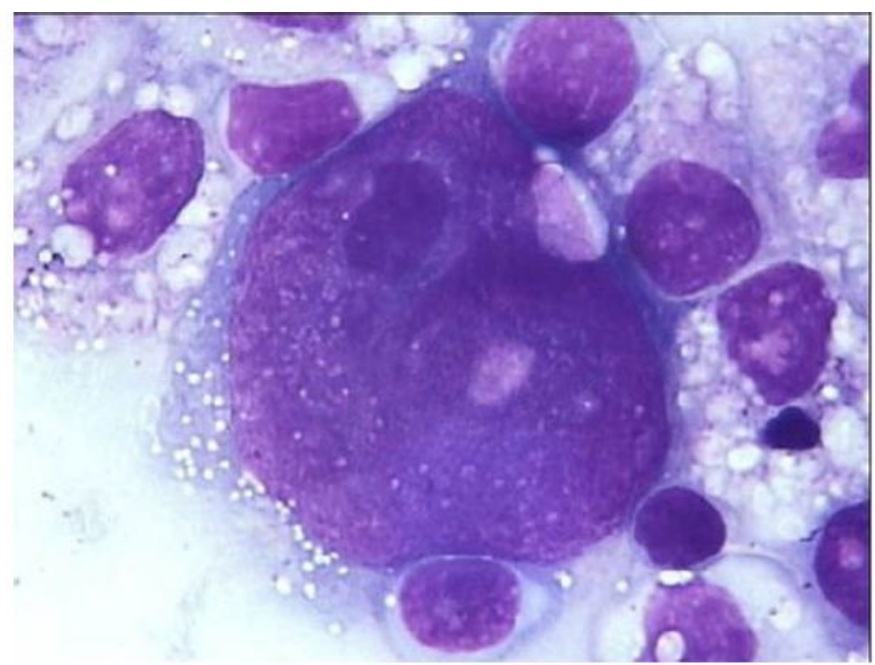

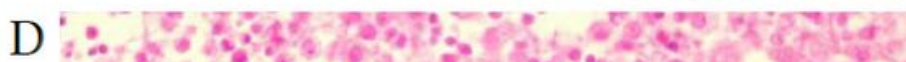

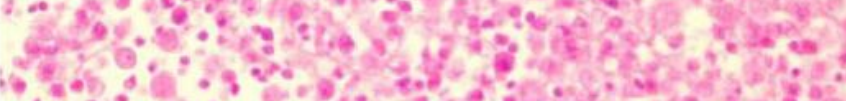

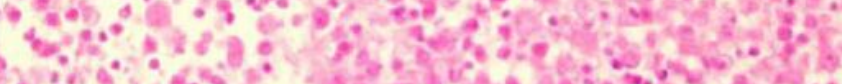

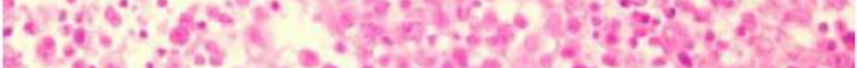

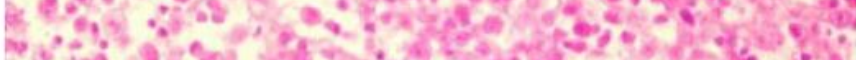

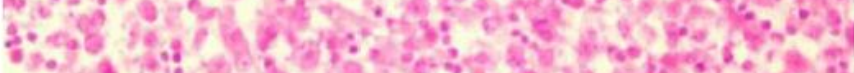

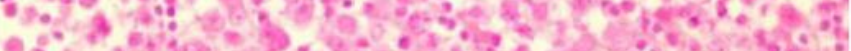

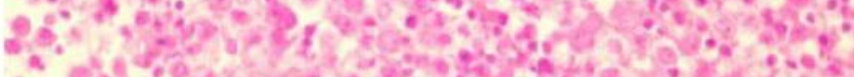

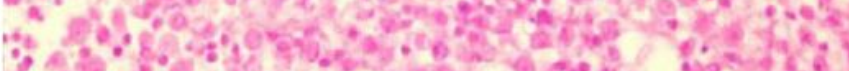

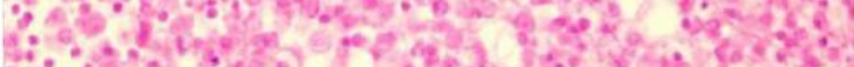

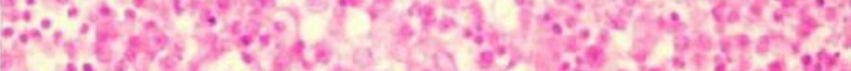

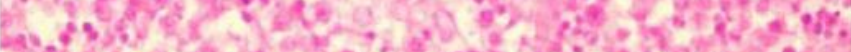

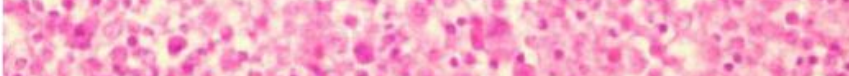

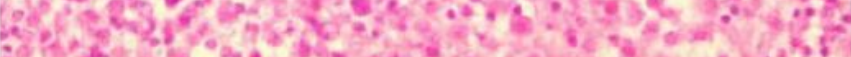

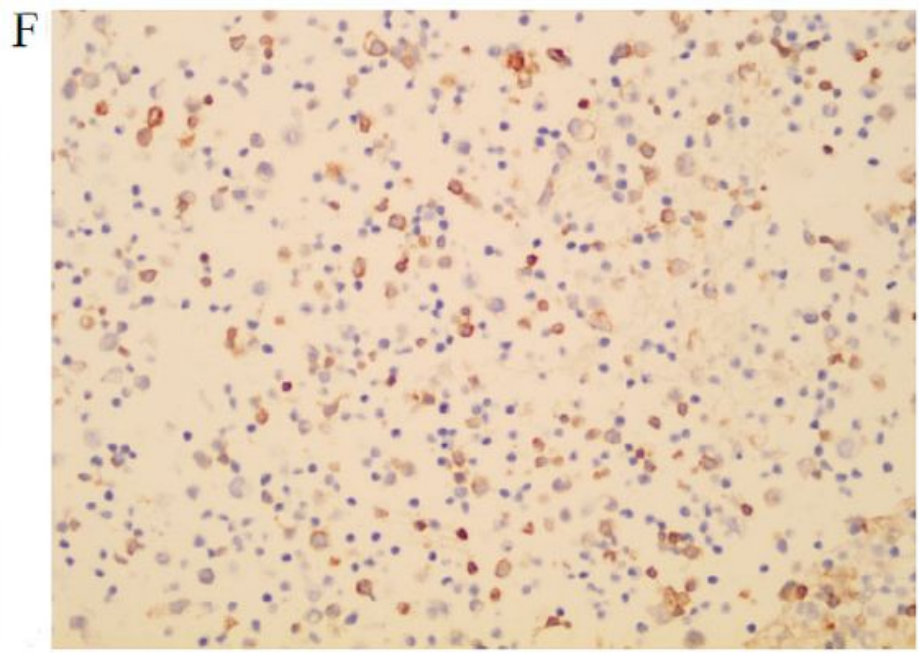

\section{Figure 2}

The cytomorphologic features of diffuse large B-cell lymphoma (DLBCL) cells in pleural effusions (PEs). Cytoplasmic or nuclear vacuoles, papillary projection of nuclei, and mitoses of DLBCL cells were easily found in PEs (A, Wright-Giemsa stain, $\times 1000)$. Sometimes DLBCL cell presented cytomorphologic features similar to undifferentiated carcinoma or sarcoma (B, Wright-Giemsa stain, $\times 1000)$. Liquid-based preparation (ThinPrep) showed the predominance of immature lymphocytes (C, papanicolaou stain, $\times 400)$. Cell block 
sections showed clusters of immature lymphocytes $D$, haematoxylin and eosin stain, $\times 400)$. The DLBCL cells were strong positive of CD20 (E), and CD79a (F) (ICC stain, $\times 400)$.
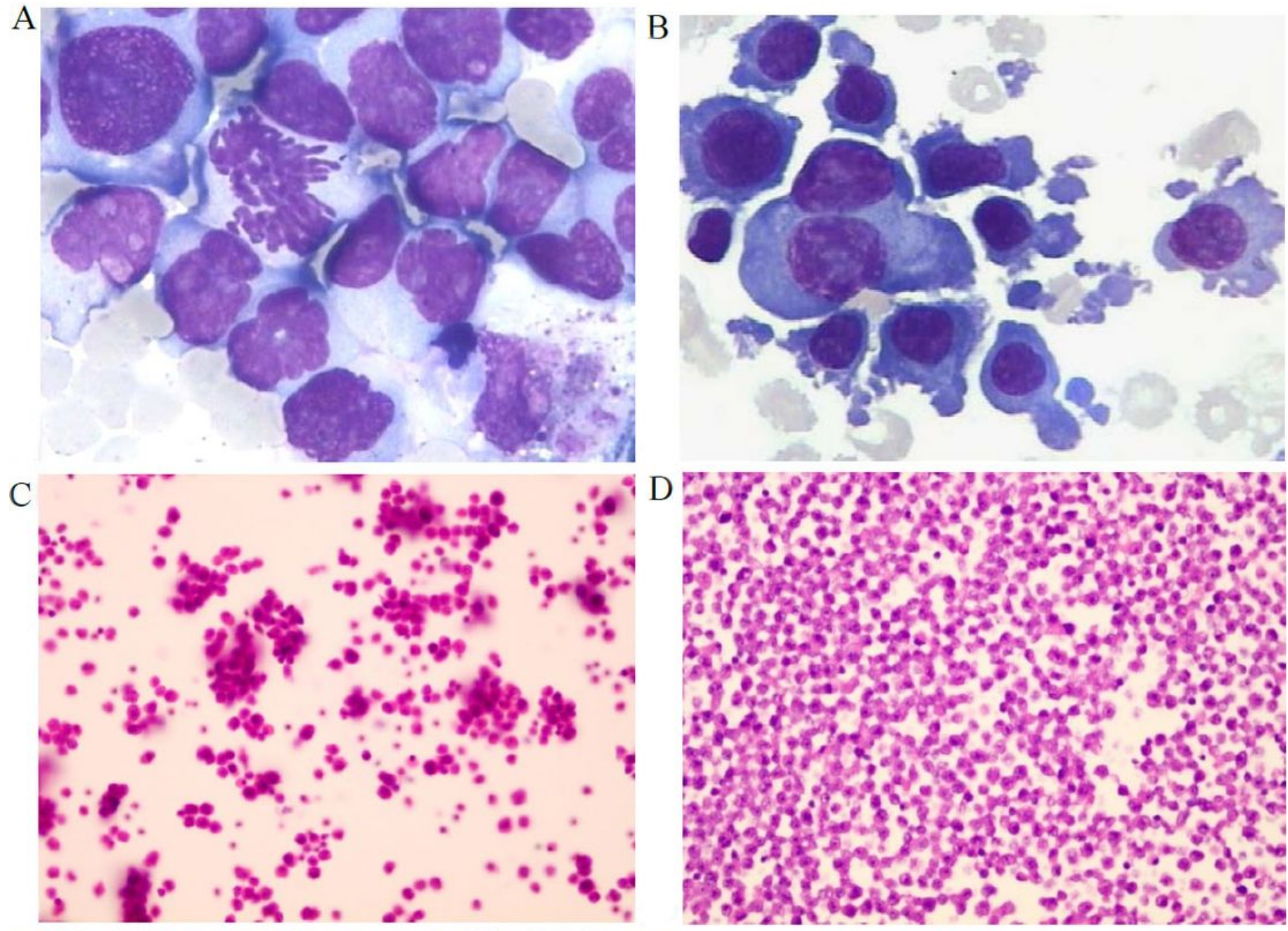

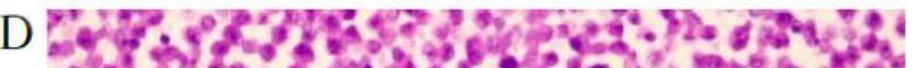
0 .

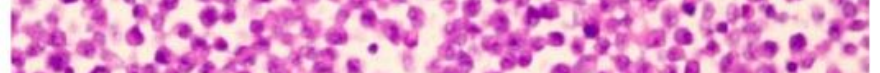

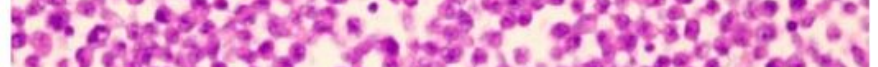

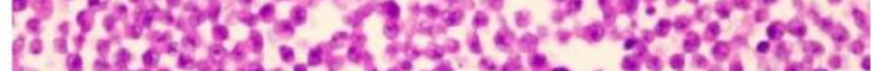

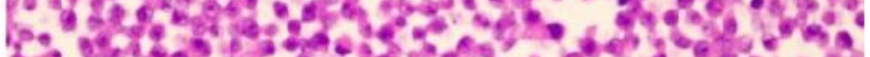

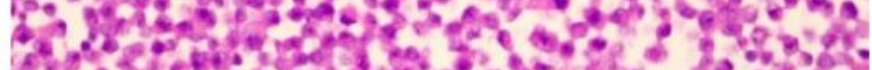

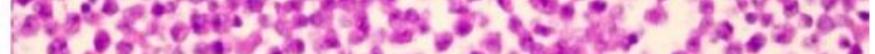
10 .

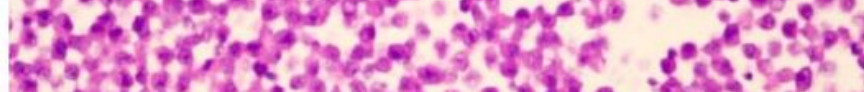

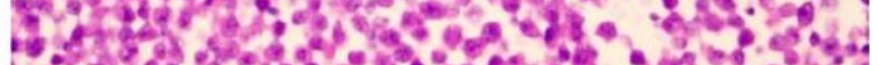

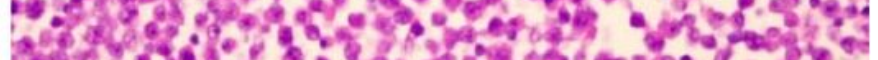

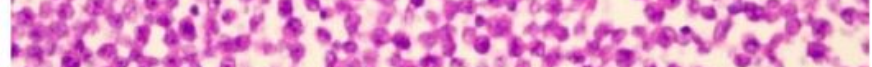

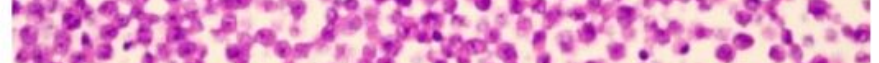

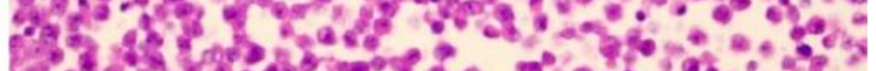
$3 x^{2}$.

$\mathrm{E}$.

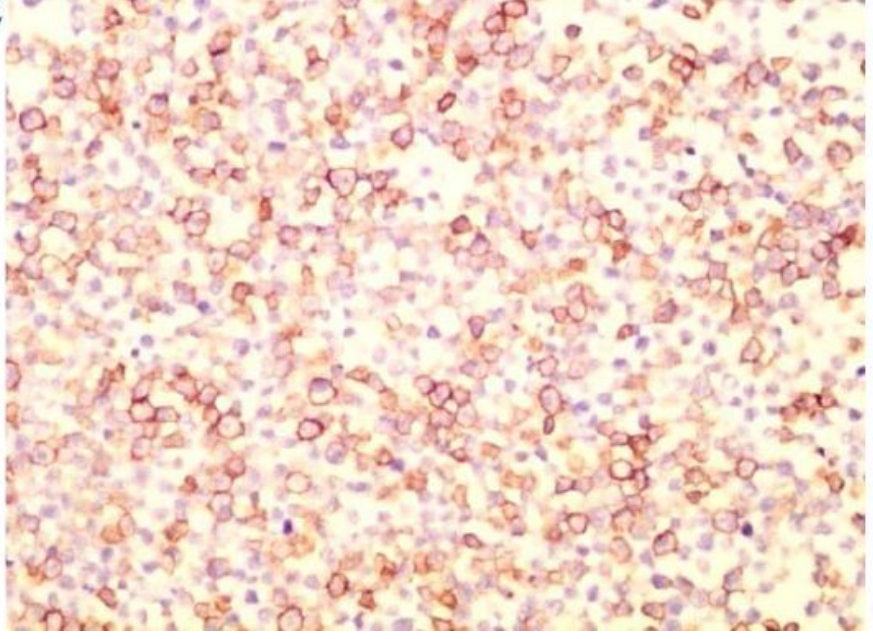

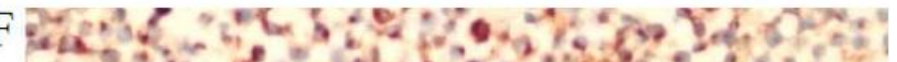

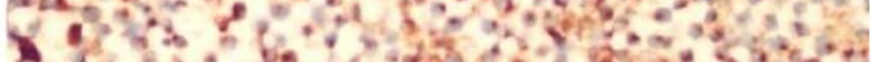

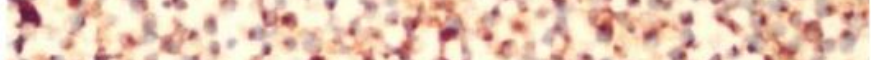

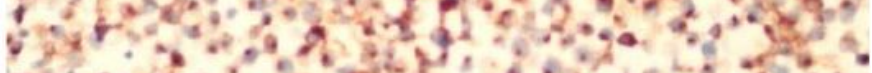

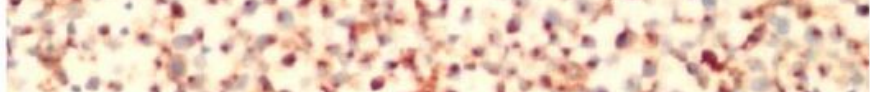

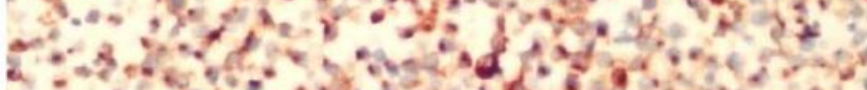

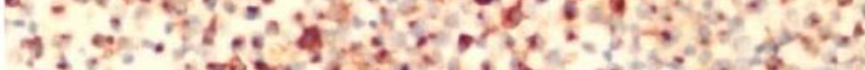
3.

\section{Figure 3}

The cytomorphologic features of myeloma cells in pleural effusions (PEs). In PEs involved with myeloma, immature plasma cells were more frequently found, and nuclear polymorphism, mitoses and apoptosis were easily found (A-B, Wright-Giemsa stain, $\times 1000)$. Liquid-based preparation (ThinPrep) showed the predominance of plasma cells (C, haematoxylin and eosin stain, $\times 400)$. Cell block section showed clusters 
of plasma cells $(D$, haematoxylin and eosin stain, $\times 400)$. The myeloma cells were strong positive of CD138 (E) and lambda (F) (ICC stain, $\times 400)$.
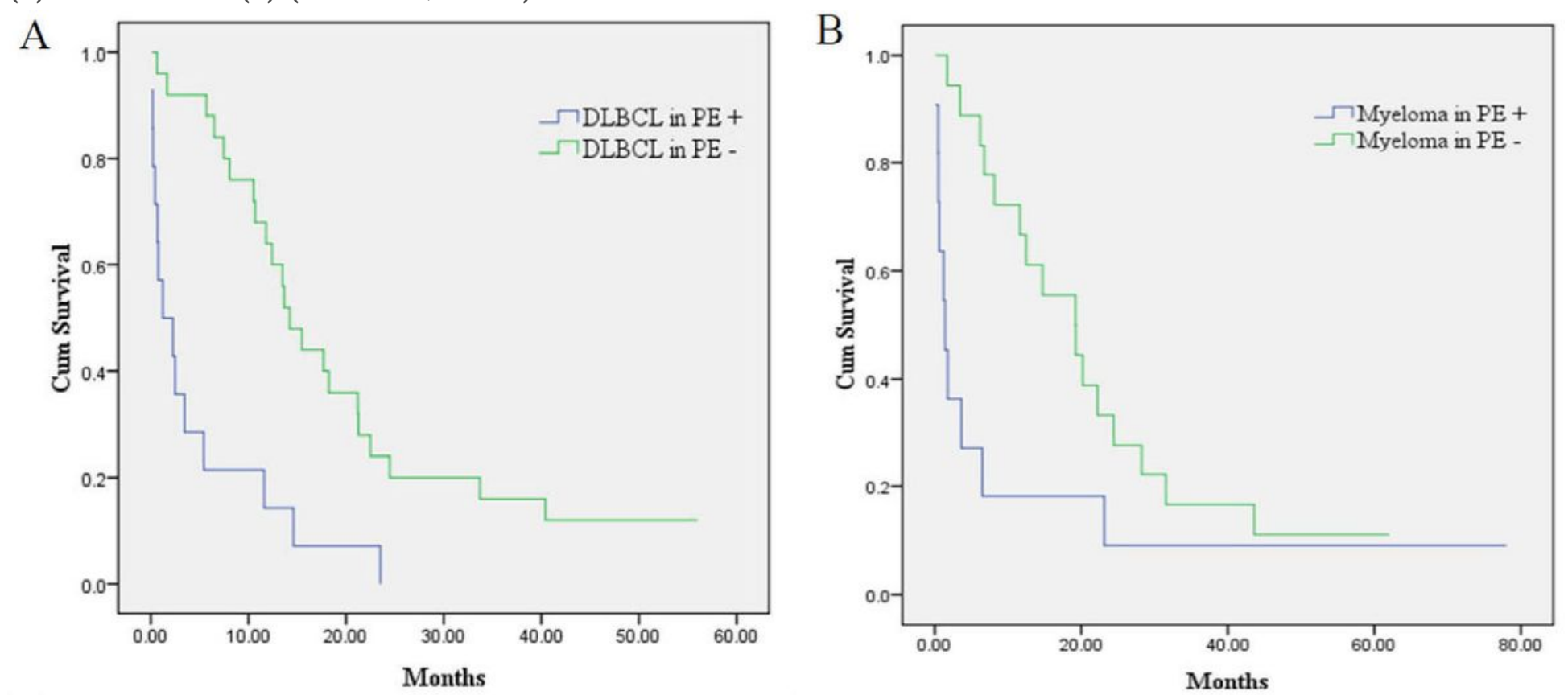

\section{Figure 4}

Survival analysis of diffuse large B-cell lymphoma (DLBCL) and myeloma after effusion. By Kaplan-Meier analysis, it showed that the survival time of DLBCL patients after effusion in pleural effusions positive group was significantly shorter than that in PEs negative group (median, 1.23 vs 14.43 months, $P=0.000$ ) (A), and the survival time of myeloma after effusion in PEs positive group was significantly shorter than that in PEs negative group (median, 1.4 vs 19.2 months, $P=0.029)(B)$. 